\title{
Fluorescent labeling of tRNA dihydrouridine residues: Mechanism and distribution
}

\author{
JASKIRAN KAUR, ${ }^{1,2}$ MONIKA RAJ, ${ }^{1,3}$ and BARRY S. COOPERMAN ${ }^{1,4}$ \\ ${ }^{1}$ Department of Chemistry, University of Pennsylvania, Philadelphia, Pennsylvania 19104-6323, USA \\ ${ }^{2}$ Anima Cell Metrology, Inc., Bernardsville, New Jersey 07924-2270, USA
}

\begin{abstract}
Dihydrouridine (DHU) positions within tRNAs have long been used as sites to covalently attach fluorophores, by virtue of their unique chemical reactivity toward reduction by $\mathrm{NaBH}_{4}$, their abundance within prokaryotic and eukaryotic tRNAs, and the biochemical functionality of the labeled tRNAs so produced. Interpretation of experiments employing labeled tRNAs can depend on knowing the distribution of dye among the DHU positions present in a labeled tRNA. Here we combine matrixassisted laser desorption/ionization mass spectroscopy (MALDI-MS) analysis of oligonucleotide fragments and thin layer chromatography to resolve and quantify sites of DHU labeling by the fluorophores Cy3, Cy5, and proflavin in Escherichia coli tRNA $^{\text {Phe }}$ and $E$. coli tRNA $^{\text {Arg }}$. The MALDI-MS results led us to re-examine the precise chemistry of the reactions that result in fluorophore introduction into tRNA. We demonstrate that, in contrast to an earlier suggestion that has long been unchallenged in the literature, such introduction proceeds via a substitution reaction on tetrahydrouridine, the product of $\mathrm{NaBH}_{4}$ reduction of DHU, resulting in formation of substituted tetrahydrocytidines within tRNA.
\end{abstract}

Keywords: tRNA; dihydrouridine; tetrahyhydrocytidine; Cy3/Cy5/proflavin; MALDI

\section{INTRODUCTION}

Fluorescent-labeled tRNAs have been used extensively in mechanistic studies of in vitro protein synthesis, and, more recently, to monitor protein synthesis within intact cells (S Barhoom, J Kaur, BS Cooperman, NI Smorodinsky, Z Smilansky, M Ehrlich, and O Elroy-Stein, in prep.). For such studies, fluorescent groups have been introduced in a variety of ways, either by derivatization of the amino acid with which the tRNA is charged (McIntosh et al. 2000, Woolhead et al. 2004) or via covalent attachment of fluorophores to modified nucleosides having unique chemical reactivity (Schleich et al. 1978; Blanchard et al. 2004a,b; Bieling et al. 2006; Munro et al. 2007; Fei et al. 2008; Pan et al. 2009; Bharill et al. 2011; Chen et al. 2011). Of the latter, dihydrouridine (DHU) is by far the most abundant, occurring in $>90 \%$ of both prokaryotic and eukaryotic tRNAs, at stoichiometries of 1-6 DHU/tRNA, with most being found within the D-loops of tRNAs. Moreover, introduction of $\mathrm{NH}_{2}$-containing fluorophore nucleophiles

${ }^{3}$ Present address: Department of Chemistry, New York University, New York, NY 10003, USA.

${ }^{4}$ Corresponding author.

E-mail cooprman@pobox.upenn.edu.

Article published online ahead of print. Article and publication date are at http://www.rnajournal.org/cgi/doi/10.1261/rna.2670811. into $\mathrm{DHU}$ positions via $\mathrm{NaBH}_{4}$ reduction results in labeled tRNAs retaining substantial activity in protein synthesis (Pape et al. 1998; Savelsbergh et al. 2003; Betteridge et al. 2007; Grigoriadou et al. 2007a,b; Pan et al. 2007).

Earlier studies made extensive use of proflavin derivatives of tRNA. More recently we reported (Pan et al. 2009) a procedure employing hydrazides to introduce Cy3 and Cy5 dyes, suitable for both ensemble and single molecule FRET (smFRET) studies, into DHU positions of tRNA. Knowing the distribution of dye among the DHU positions present in a labeled tRNA can be important for interpretation of FRET results, as FRET efficiency values are dependent on the distance between the two fluorophores. In addition, dye labeling of tRNA can affect its functional activity, and such functional effects can be position dependent. Wintermeyer and Zachau (1979) utilized a combination of ion-exchange chromatography, disk-gel electrophoresis, and thin layer chromatography of radioactively labeled oligonucleotide fragments generated by the endonuclease digestion to determine the distribution of ethidium and proflavin dyes between the 16 and 17 DHU positions in yeast tRNA ${ }^{\text {Phe }}$. Here we carry out similar but more facile analyses of $\mathrm{Cy} 3$, Cy5, and proflavin derivatives of Escherichia coli $\mathrm{tRNA}^{\mathrm{Arg}}$ and E. coli tRNA ${ }^{\text {Phe }}$, each of which has two DHU/tRNA, at positions 17 and 20a, and 16 and 20, respectively (see Supplemental Material), by combining MALDI-MS analysis 
of endonuclease-generated oligonucleotide fragments (Polo and Limbach 1998, Kirpekar et al. 2000, Berhane and Limbach 2003a,b, Hartmer et al. 2003, Meng and Limbach 2004, Zhao and $\mathrm{Yu}$ 2004, Hossain and Limbach 2007, Hengesbach et al. 2008, Hossain and Limbach 2009) and thin layer chromatography.

Despite the extensive use of fluorescent tRNAs labeled at DHU positions, the precise chemistry of the reaction leading to fluorophore introduction into these positions has been unclear. As part of this work reported below we have carried out model chemistry, which, combined with the MALDI-MS analysis of labeled tRNAs, demonstrates that such introduction via $\mathrm{NaBH}_{4}$ reduction results in a substitution reaction on tetrahydrouridine by reagents having the general structure $\mathrm{RNH}_{2}$, resulting in formation of a substituted tetrahydrocytidine.

\section{RESULTS AND DISCUSSION}

\section{Dihydrouridine (DHU) reduction and benzohydrazide substitution}

A clear understanding of the chemistry of DHU reduction and subsequent reaction with $\mathrm{RNH}_{2}$-containing compounds is important for the work reported below on characterizing fluorescent-labeled tRNAs. Earlier studies of $\mathrm{NaBH}_{4}$ reduction of DHU reported two different products for reactions carried out under different conditions. The principal product formed using a $1: 1$ $\mathrm{NaBH}_{4}: \mathrm{DHU}$ stoichiometry for $35 \mathrm{~min}$ at $0^{\circ} \mathrm{C}$ is tetrahydrouridine (THU) (Hanze 1967), a well known inhibitor of cytidine deaminase (Wentworth and Wolfenden 1975) that is used in combination cancer chemotherapy ( $\mathrm{Li}$ et al. 2009), whereas more forcing conditions (2:1 stoichiometry, $2 \mathrm{~h}$, room temperature) afforded the doubly reduced, ringopened product $\mathrm{N}$-( $\beta$-D-ribofuranosy1)- $\mathrm{N}$ - $(\gamma$-hydroxypropyl)urea (Cerutti et al. 1968). In the work reported here, we carried out DHU reduction using conditions typically used in tRNA labeling experiments (a large molar excess of $\mathrm{NaBH}_{4}, 1 \mathrm{~h}$ incubation, $0^{\circ} \mathrm{C}$ (Wintermeyer and Zachau 1979; Pan et al. 2009). A single product formed in high yield was seen by TLC analysis that corresponded to THU, as characterized by NMR and IR spectra, with no evidence of $\mathrm{N}$-( $\beta$-D-ribofuranosy1)- $\mathrm{N}$-( $\gamma$-hydroxypropy1)urea formation (see Materials and Methods). THU reaction with benzohydrazide, carried out in a water:methanol (0.2:5.0) mixed solvent that was acidified with acetic acid $\left(4 \mathrm{~h}, 40^{\circ} \mathrm{C}\right)$ led to conversion of THU to $\mathrm{N}^{4}$-benzoamido-tetrahydrocytidine (1) (Fig. 1), as characterized by NMR and IR spectra. Overall formation of $\mathbf{1}$ from DHU is summarized in Figure 1. Under the mild acid conditions that are required for step 2, substitution of the hydrazide for the hydroxy group may proceed via reversible general-acid catalyzed formation of dehydrated THU, followed by a nucleophilic attack on the resulting Schiff base, as

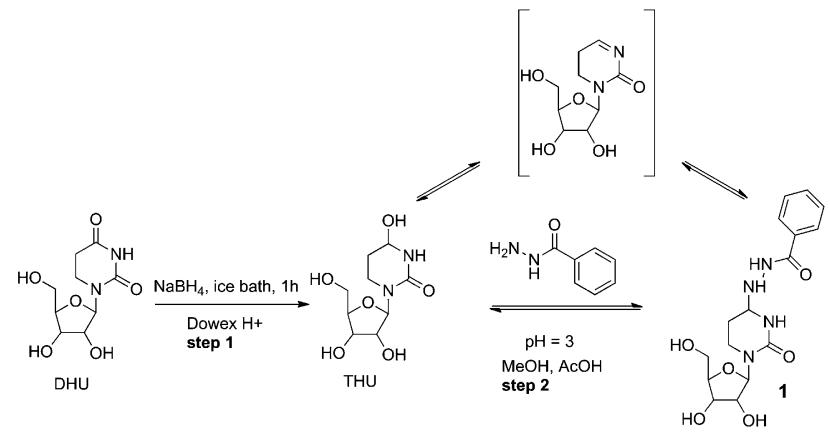

FIGURE 1. Synthetic scheme for $\mathrm{N}^{4}$-benzoamido-tetrahydrocytidine (1) preparation. The bracketed structure is a plausible intermediate in step 2.

indicated. To our knowledge, this is the first report of a nucleophilic substitution reaction on THU.

\section{Cy3, Cy5, and proflavin labeling of $E$. coli tRNA ${ }^{\text {Arg }}$ and $E$. coli tRNA ${ }^{\text {Phe }}$}

Dye labeling of tRNAs was carried out essentially as described (Pan et al. 2009), using either Cy3 hydrazide, Cy5 hydrazide, or proflavin.

\section{MALDI analyses of endonuclease digests of labeled tRNAs}

\section{Optimization of digestion conditions}

We used E. coli tRNA ${ }^{\text {Arg }}$ to identify RNase T1 and RNase A digestion conditions leading to the generation of virtually the full complement of expected oligonucleotides containing $\geq 2$ nucleotides, as identified by MALDI analysis (Table 1). Starting with conditions described by Hossain and Limbach (2007), we found that shorter incubation times, important for retention of fluorescent label, were sufficient for complete digestion (10 min vs. 1-2 h, 1 U RNase A/ $\mu \mathrm{g}$ tRNA or 50U RNase T1/ $\mu \mathrm{g}$ tRNA) of unmodified tRNA for both enzymes and generated all products as the $3^{\prime}$-linear phosphates. However, increased RNase A (5 U RNase A/ $\mu$ g tRNA) was required for RNase A cleavage at positions of DHU derivatized with either $\mathrm{Cy} 3$ or Cy5. RNase A catalyzes RNA hydrolysis via $2^{\prime}, 3^{\prime}$-cyclic phosphate formation and hydrolysis. The higher RNase A level led to the detection of Cy3/Cy5-labeled fragments from modified E. coli tRNA $^{\text {Phe }}$ as $3^{\prime}$-linear phosphates, although labeled fragments from modified E. coli $\mathrm{tRNA}^{\mathrm{Arg}}$ were only detected as $2^{\prime}, 3^{\prime}$-cyclic phosphates (Table 2). Our results indicate that the hydrolysis step is particularly sensitive to inhibition by DHU derivatization and that, given the differences observed in the digestions of labeled tRNA ${ }^{\text {Phe }}$ and tRNA ${ }^{\mathrm{Arg}}$, the strength of such inhibition is likely to be sequence dependent.

\section{MALDI analysis of the RNase digestion products} of unlabeled tRNA ${ }^{\text {Arg }}$

MALDI analyses of RNase T1 and RNase A digestions of unlabeled tRNA ${ }^{\text {Arg }}$ show major and minor peaks (Fig. 2) 
TABLE 1. MALDI peaks from RNase digested unlabeled tRNA

\begin{tabular}{|c|c|c|}
\hline Oligonucleotides sequence & $M+H$ & Peak intensity \\
\hline \multicolumn{3}{|l|}{ RNase $\mathrm{T} 1$ digestion } \\
\hline${ }^{59}$ AAUCCUCCCGp ${ }^{68}$ & 3159.4 & Major \\
\hline${ }^{26} \cup A C U C G p^{31}$ & 1915.3 & Major \\
\hline${ }^{2}$ CAUCCGp $^{7}$ & 1914.2 & Major \\
\hline${ }^{38} \mathrm{~m}^{2}$ AACCG $\mathrm{p}^{42}$ & 1646.3 & Major \\
\hline${ }^{33} \mathrm{CUICG}^{37}$ & 1610.2 & Minor \\
\hline${ }^{11}$ CUCAGp ${ }^{15}$ & 1609.2 & Minor \\
\hline${ }^{73} \mathrm{CACCA}^{77}$ & 1512.2 & Major \\
\hline${ }^{47} \mathrm{~m}^{7} \mathrm{GXCG} \mathrm{p}^{50}$ & 1435.2 & Minor \\
\hline${ }^{20}$ ADAGp ${ }^{23}$ & 1330.2 & Major \\
\hline${ }^{55} \mathrm{~m}^{5}$ UPCGp ${ }^{58}$ & 1295.2 & Minor \\
\hline${ }^{8} \mathrm{~s}^{4} \mathrm{UAGp} \mathrm{p}^{10}$ & 1015.1 & Minor \\
\hline${ }^{70} \mathrm{AUGp} \mathrm{p}^{72}$ & 999.2 & Major \\
\hline${ }^{16} \mathrm{CDGp}^{18}$ & 977.2 & Minor \\
\hline${ }^{43} \mathrm{AGp}^{44}$ & 693.2 & Major \\
\hline \multicolumn{3}{|l|}{${ }^{24} \mathrm{AGp}^{25}$} \\
\hline \multicolumn{3}{|l|}{${ }^{52} \mathrm{AGp}^{53}$} \\
\hline${ }^{45} \mathrm{CGp}^{46}$ & 669.1 & Minor \\
\hline \multicolumn{3}{|l|}{ RNase $A$ digestion } \\
\hline${ }^{49}$ GGAGGTp ${ }^{54}$ & 2048.2 & Major \\
\hline${ }^{21}$ AGAGUp $^{25}$ & 1673.2 & Major \\
\hline${ }^{45} \mathrm{Gm}^{7} \mathrm{Gacp}^{3} \cup C \mathrm{p}^{48}$ & 1435.2 & Major \\
\hline${ }^{18} \mathrm{GGADp}^{20 a}$ & 1346.2 & Minor \\
\hline${ }^{67} \mathrm{GGAUp}^{70}$ & 1344.2 & Minor \\
\hline${ }^{41}$ GAGCp $^{44}$ & 1343.2 & Minor \\
\hline${ }^{36} \mathrm{Gm}^{2} \mathrm{AACp}{ }^{39}$ & 1341.2 & Major \\
\hline${ }^{57} \mathrm{GAAUp} \mathrm{p}^{60}$ & 1328.2 & Major \\
\hline${ }^{30} \mathrm{GGCp} \mathrm{p}^{32}$ & 1014.1 & Minor \\
\hline${ }^{9} \mathrm{AGCp}^{11}$ & 998.2 & Major \\
\hline \multicolumn{3}{|l|}{${ }^{14} \mathrm{AGCp}^{16}$} \\
\hline${ }^{1} \mathrm{GCp}{ }^{2}$ & 669.1 & Minor \\
\hline \multicolumn{3}{|l|}{${ }^{71} \mathrm{GCp} p^{72}$} \\
\hline${ }^{3} \mathrm{AUp}{ }^{4}$ & 654.1 & Major \\
\hline \multicolumn{3}{|l|}{${ }^{34} \mathrm{ICp}^{35}$} \\
\hline${ }^{26} \mathrm{ACp} \mathrm{p}^{27}$ & 653.1 & Major \\
\hline \multicolumn{3}{|l|}{${ }^{73} \mathrm{ACp}^{74}$} \\
\hline${ }^{55} \mathrm{PsiCp}{ }^{56}$ & 630.1 & $\mathrm{NI}^{\mathrm{b}}$ \\
\hline
\end{tabular}

$\geq 2$ nucleotides; single nucleotides could not be resolved from background; D containing oligonucleotides are indicated in bold. ${ }^{\mathrm{b}}$ Not identified.

corresponding to expected fragments on RNase T1 digestion (Table 1), including the DHU containing nucleotides, $\mathrm{AD}^{20 \mathrm{a}} \mathrm{AG}(\mathrm{m} / \mathrm{z} 1330.2)$ (Fig. $\left.2 \mathrm{~A}\right)$ and $\mathrm{CD}^{17} \mathrm{G}(\mathrm{m} / \mathrm{z}$ 977.2) (Fig. 2B). RNase A digestion shows a minor peak at $m / z 1346.2$ for the GGAD fragment. High background prevented the assignment of a peak to the expected mononucleotide $\mathrm{D}^{17}$.

\section{MALDI and MALDI-TOF-TOF analysis of RNase T1 digestion products of reduced and dye-labeled tRNA ${ }^{\text {Arg }}$}

\section{$\mathrm{NaBH}_{4}$-reduced $\mathrm{RN} A^{\text {Arg }}$}

With respect to the major peaks seen in Figure $2 \mathrm{~A}, \mathrm{NaBH}_{4}$ reduction leads to selective disappearance of only the
1330.2 peak, corresponding to $\mathrm{AD}^{20 \mathrm{a}} \mathrm{AG}$. Examination of the 1330 region (Fig. 3) shows that the disappearance of the 1330.2 peak is accompanied by the appearance of two new peaks at 1314.2 and 1316.2 , and an apparent increase in the relative intensity of the peak at $m / z 1332.2$. As the 1332.2 peak in the unreduced sample is an isotopic peak of the major peak at 1330.2, the increase in its relative intensity on $\mathrm{NaBH}_{4}$ reduction is consistent with the formation of a THU at position 20a, and the 1314.2 peak is consistent with the dehydration of THU to form the dihydropyrimidin-2-one, prior to and/or during mass spectral analysis. Dehydration of THU in the mass spectrometer, presumably to give the dihydropyrimidin-2-one, has previously been described by Hanze (1967). Although we are unable to assign a structure to the new peak at 1316.2 with confidence, one possibility is that it corresponds to reduction of the dihydropyrimidin-2-one to form the tetrahydropyrimidin-2-one. Consistent with the model DHU reduction chemistry reported above, no new peak is seen at $\mathrm{m} / \mathrm{z}$ 1334.2, which would have corresponded to the formation of $\mathrm{N}$-( $\beta$-D-ribofuranosy1)-N-( $\gamma$-hydroxypropy1)urea at position 20a.

\section{Cy3- and Cy5-labeled tRNA $A^{\text {Arg }}$}

With respect to unlabeled $\mathrm{tRNA}^{\mathrm{Arg}}$, MALDI analysis of Cy3- and Cy5-labeled tRNA ${ }^{\text {Arg }}$ leads to the appearance of two new major peaks at $m / z 1958.5$ and $m / z 1984.5$, respectively (Fig. 4A,B), and two new minor peaks at $m / z$ 1605.5 and $m / z$ 1631.5, respectively (Fig. 4C,D). MALDITOF-TOF analyses of these four new peaks (Fig. 4E-H) show that each decomposes to give two new peaks, one corresponding to the parent nucleotide containing dehydrated THU in place of DHU (E, F: $\mathrm{AD}^{20 \mathrm{a}} \mathrm{AG}, m / z$ 1314.2; G, H: $C D^{17} \mathrm{G}, m / z$ 961.2) and one corresponding either to Cy3-hydrazide $(m / z$ 645.3) (Fig. 4E,G) or Cy5-hydrazide $(m / z$ 671.3) (Fig. 4F,H). These mass spectral analyses, when coupled with the DHU reduction results presented previously, support the mechanism for dye labeling of tRNA that parallels Figure 1, in which the incoming hydrazide displaces the 4-hydroxyl group of THU, giving rise to a substituted tetrahydrocytidine (THC).

\section{MALDI analyses of other RNase digestion products}

MALDI and MALDI-TOF-TOF analyses similar to those described earlier were also carried out on RNase A digests of unlabeled and Cy3- and Cy5-labeled tRNA ${ }^{\text {Arg }}$ and of RNase T1 and RNase A digests of Cy3- and proflavinlabeled tRNA ${ }^{\text {Phe }}$. In each case, the only dye-labeled peaks are derived from oligonucleotides that in underivatized tRNA include a DHU residue, have masses corresponding to a substituted tetrahydrocytidine product as depicted in Figure 1 (with the fluorophore $\mathrm{RNH}_{2}$ replacing benzohydrazide), and decompose on MALDI-TOF-TOF analysis 
TABLE 2. MALDI determinations of dye-labeled oligonucleotides derived from

\begin{tabular}{|c|c|c|c|c|}
\hline $\begin{array}{l}\text { tRNA } \\
\text { fragment }\end{array}$ & Unmodified & $\begin{array}{c}\text { Cy3 hydrazide } \\
\text { adduct } \\
\text { TOF:TOF }\end{array}$ & $\begin{array}{c}\text { Cy5 hydrazide } \\
\text { adduct } \\
\text { TOF:TOF }\end{array}$ & $\begin{array}{l}\text { Proflavin } \\
\text { adduct } \\
\text { TOF:TOF }\end{array}$ \\
\hline \multicolumn{5}{|l|}{ tRNA ${ }^{\text {Arg: }}: T 1$} \\
\hline$A D^{20 a} A G 3^{\prime} P$ & 1330.2 & $\begin{array}{l}1958.5 \\
1314.2,645.3\end{array}$ & $\begin{array}{l}1984.5 \\
1314.2,671.3\end{array}$ & \\
\hline $\mathrm{CD}^{17} \mathrm{G} 3^{\prime} \mathrm{P}$ & 977.2 & $\begin{array}{l}1605.5 \\
961.2,645.3\end{array}$ & $\begin{array}{l}1631.5 \\
961.2,671.3\end{array}$ & \\
\hline \multicolumn{5}{|l|}{ tRNA Arg: $A$} \\
\hline $\mathrm{GGAD}^{20 a} 3^{\prime} P$ & 1346.2 & $\begin{array}{l}1956.6>^{\mathrm{a}} \\
1312.2,645.3\end{array}$ & $\begin{array}{l}1982.2>^{\mathrm{a}} \\
1312.2,671.3\end{array}$ & \\
\hline$D^{17}$ & b & $\begin{array}{l}937.4>^{a} \\
645.3\end{array}$ & $\begin{array}{l}963.4>^{a} \\
671.3\end{array}$ & \\
\hline \multicolumn{5}{|l|}{ tRNA ${ }^{\text {Phe: }}: T 1$} \\
\hline $\mathrm{D}^{16} \mathrm{CG} 3^{\prime} \mathrm{P}$ & 977.2 & $\begin{array}{l}1605.6 \\
961.2,645.3\end{array}$ & & $\begin{array}{l}1170.5 \\
961.2,210.3\end{array}$ \\
\hline $\mathrm{D}^{20} \mathrm{AG} 3^{\prime} \mathrm{P}$ & 1001.2 & $\begin{array}{l}1629.5 \\
985.2,1629.5\end{array}$ & & $\begin{array}{l}1194.5 \\
985.2,501.1,{ }^{\mathrm{C}} \\
210.3\end{array}$ \\
\hline \multicolumn{5}{|l|}{ tRNA ${ }^{\text {Phe: }}: A$} \\
\hline $\mathrm{AGD}^{16} 3^{\prime} \mathrm{P}$ & 1001.2 & $\begin{array}{l}1629.5 \\
985.2,645.3\end{array}$ & & $\begin{array}{l}1194.5 \\
985.2,210.3\end{array}$ \\
\hline $\mathrm{GGD}^{20} 3^{\prime} \mathrm{P}$ & 1017.2 & $\begin{array}{l}1645.5 \\
1001.1,645.3\end{array}$ & & $\begin{array}{l}1210.5 \\
1001.2,210.3\end{array}$ \\
\hline
\end{tabular}

Overall labeling stoichiometries (dye/tRNA): Cy3-tRNA ${ }^{\text {Arg }}$ (1.06); Cy5-tRNA ${ }^{\text {Arg }}(0.75)$; Cy3tRNA $^{\text {Phe }}$ (1.2); prf-tRNA ${ }^{\text {Arg }}$ (1.6).

${ }^{a} 2^{\prime}, 3^{\prime}$ Cyclic phosphate indicated by the symbol $>$.

${ }^{\mathrm{b}}$ The peak due to DHU is obscured by background.

'Unassigned. dye-labeled tRNAs

displacement of a putative 3-ureidopropanol product of DHU reduction. As we have seen, the reduction reaction conditions employed both here and in the later work of Wintermeyer and Zachau (1979) lead to THU rather than $\mathrm{N}$-( $\beta$-D-ribofuranosy1)-N-( $\gamma$-hydroxypropy1)urea formation. Moreover, even under more forcing reduction conditions leading to 3-ureidopropanol formation, it is not clear that $\mathrm{RNH}_{2}$ would readily displace the ureido group under the conditions employed in the earlier work of Wintermeyer and Zachau $(\mathrm{pH} 3$, $45 \mathrm{~min}, 37^{\circ} \mathrm{C}$ ). Thus, acid hydrolysis of the ureidopropanol link to the ribose proceeds to only $90 \%$ completion under much more vigorous conditions $(0.5 \mathrm{~N}$ $\mathrm{H}_{2} \mathrm{SO}_{4}, 4 \mathrm{~h}, 65^{\circ} \mathrm{C}$ ) (Cerutti and Miller 1967).

\section{Dye distributions between dihydroU positions in Cy3-labeled tRNAs}

The dye-labeled oligonucleotides produced by RNase A digestion of $\mathrm{Cy} 3-$ labeled tRNA ${ }^{\mathrm{Arg}}$ and tRNA ${ }^{\mathrm{Phe}}$ samples could be separated from each other by TLC (Fig. 5). Following elution, each band was identified as a substituted to the dehydrated THU and the dye. These results are summarized in Table 2, where the constant 16 amu difference in mass between the unmodified oligonucleotide and the dehydrated THU seen by MALDI-TOF-TOF is due to a gain of $2 \mathrm{amu}$ on reduction of DHU to THU, followed by a loss of $18 \mathrm{amu}$ on dehydration. Interestingly, replacement of DHU by a substituted THC does not prevent RNase A cleavage, as seen both by the appearance of peaks corresponding to the labeled oligonucleotides (Table 2) and the failure to detect larger oligonucleotides that would have resulted from blockage of such cleavage by substituted THC formation. Such replacement, which minimally perturbs the core tRNA structure, may account for the relatively high activity of the dye-modified tRNAs in protein synthesis assays (Pan et al. 2009).

\section{Formation of substituted tetrahydrocytidines}

The demonstration in this work that $\mathrm{RNH}_{2}$ labeling of $\mathrm{NaBH}_{4}$-reduced tRNA leads to replacement of DHU residues with substituted THCs contrasts markedly with the earlier suggestion by Wintermeyer and Zachau (1971, 1974), invoked as well by Betteridge et al. (2007) and Pan et al. (2009), that such labeling proceeds via $\mathrm{RNH}_{2}$
THC oligonucleotide by mass spectral analysis. Thus, as demonstrated by mass spectral analysis, bands 1 and 2 in Figure $5 \mathrm{~A}$ correspond to the derivatized $\mathrm{D}^{17}$ and GGAD ${ }^{20 \mathrm{a}}$, respectively (Fig. 5B), whereas bands 1 and 2 in Figure 5C correspond to the THC adducts of $\mathrm{AGD}^{16}$ and $\mathrm{GGD}^{20}$, respectively (Fig. 5D). UV spectral analysis of the eluate from each band afforded precise quantification of the amount of dye contained therein, leading to the values shown in Table 3. We conclude that the intrinsic reactivities toward dye labeling of $\mathrm{NaBH}_{4}$-reduced DHUs 17 and 20a in E. coli tRNA $^{\text {Arg }}$ are approximately equal, as are the intrinsic reactivities of $\mathrm{NaBH}_{4}$-reduced DHUs 16 and 20 in E. coli tRNA ${ }^{\text {Phe }}$.

Our results parallel earlier findings (Wintermeyer and Zachau 1979) that DHUs 16 and 17 in yeast tRNA ${ }^{\text {Phe }}$ also have similar intrinsic reactivities toward dye labeling. Taken together, both sets of results suggest that the intrinsic reactivities toward dye labeling of $\mathrm{NaBH}_{4}$-reduced DHU residues in the D-loops of tRNAs, which are found at positions 16,17, 20 and/or 20a, are generally similar. This suggestion can be relevant in interpreting the results of mechanistic studies employing fluorescent tRNAs labeled at DHU positions (e.g., utilizing smFRET [Chen et al. 2011] or ensemble FRET [Pan et al. 2009]). Such studies often 


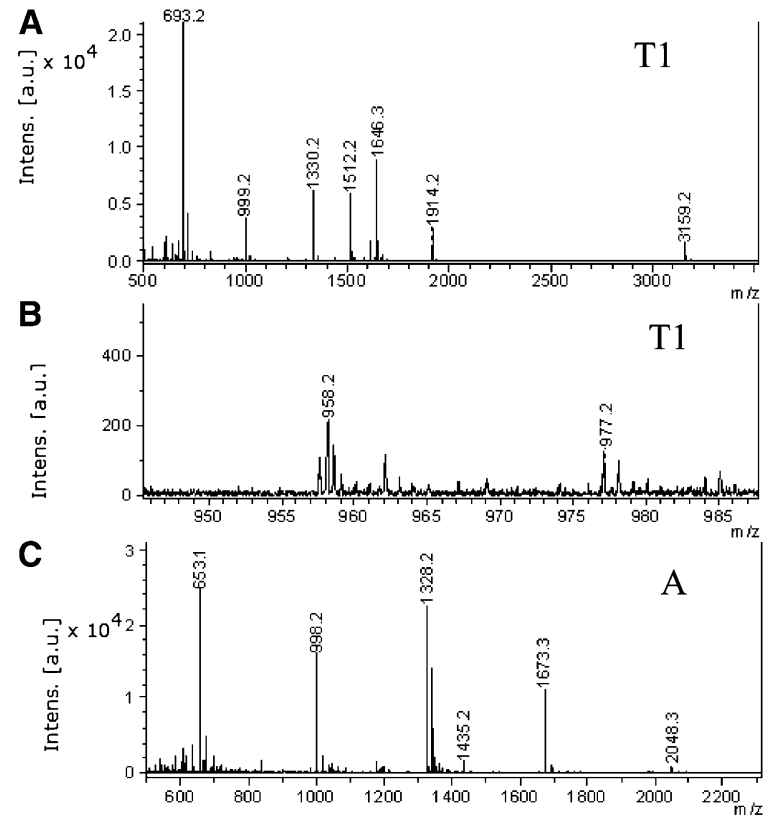

FIGURE 2. MALDI analyses of RNase digests of tRNA ${ }^{\text {Arg }}$. (A) T1 digest, major peaks; $(B)$ detail of $860-1000 \mathrm{~m} / z$ region of T1 digest, showing presence of minor peak at $977.2 \mathrm{~m} / z$, corresponding to $\mathrm{CD}^{17} \mathrm{G} 3^{\prime} \mathrm{P} ;(C)$ A digest, major peaks.

utilize tRNA preparations containing $\sim 1$ dye/tRNA. As most tRNAs contain more than one DHU/tRNA, such preparations will, in general be heterogeneous, with fluorescent label spread approximately evenly over the available DHU positions. Investigators utilizing such labeled tRNAs should be mindful of the possible effects such heterogeneity could have on measured functional activities and fluorescence properties. Resolution of at least some of the potential problems raised by such heterogeneity may be achievable via comparisons of results obtained using labeled tRNAs that have DHUs at different D-loop positions (e.g., tRNA ${ }^{\text {Phe }}$ from E. coli and yeast, which have DHUs at positions 16/20 and 16/17, respectively).

\section{SUMMARY}

Here we demonstrate that, in contrast to an earlier suggestion in the literature, labeling of tRNAs by $\mathrm{RNH}_{2}$-containing dyes at $\mathrm{NaBH}_{4}$-reduced DHU positions proceeds via initial tetrahydrouridine formation, followed by a substitution reaction that yields a substituted tetrahydrocytidine. We also describe a method, based on mass spectral and TLC analyses, for identifying and quantifying sites of labeling by $\mathrm{RNH}_{2}-$ containing dyes within $\mathrm{NaBH}_{4}$-reduced tRNAs that does not require the use of radioactive isotopes. Application of this method to dye-labeled derivatives of $E$. coli $\mathrm{tRNA}^{\mathrm{Arg}}$ and tRNA $^{\text {Phe }}$, both of which have two DHU residues, shows that, in each case, the two residues have very similar intrinsic reactivities toward labeling.

\section{MATERIALS AND METHODS}

E. coli $\mathrm{tRNA}^{\mathrm{Arg}}$ and E. coli $\mathrm{tRNA}^{\text {Phe }}$ were purchased from Chemical Block. Diammonium hydrogen citrate (DAHC), 2,4,6trihydroxyacetophenone (THAP), uridine, $\mathrm{NaBH}_{4}$, proflavin, Dowex X 50 and benzohydrazide were purchased from SigmaAldrich. RNases T1 and A were used as obtained from Roche Molecular Biochemicals. Cy3-hydrazide, Cy5-hydrazide were from GE healthcare. Dihydrouridine was synthesized by reduction of uridine as described by Paryzek and Tabaczka (2001).

\section{Synthesis of tetrahydrouridine (THU)}

$\mathrm{NaBH}_{4}$ (10 equiv) was added to $1 \mathrm{~g}$ of DHU dissolved in $0.5 \mathrm{~mL}$ of water at $0^{\circ} \mathrm{C}$, and incubation was continued for $1 \mathrm{~h}$ with stirring. The reaction was quenched by raising the $\mathrm{pH}$ to 4 via gradual addition of protonated Dowex $\mathrm{X} 50$ at $0^{\circ} \mathrm{C}$. Filtration followed by lyophilization afforded a white solid ( $85 \%$ yield), that gave a single spot on analytical TLC analysis (Silica gel, 50\% MeOH/DCM, $\mathrm{Rf}=0.4, \mathrm{p}$-anisaldehyde detection) identified as THU by IR and ${ }^{1} \mathrm{H}$ NMR spectra: IR (KBr) Vmax cm ${ }^{-1}: 3323,2930,1641$, 1504, 1073, 755; ${ }^{1} \mathrm{H}$ NMR $\left(400 \mathrm{MHz}, \mathrm{D}_{2} \mathrm{O}\right) \delta 1.75-1.77(\mathrm{~m}, 1 \mathrm{H}$, $\left.\mathrm{C}_{5} \mathrm{H}_{\mathrm{a}}\right), 1.96-2.03\left(\mathrm{~m}, 1 \mathrm{H}, \mathrm{C}_{5} \mathrm{H}_{\mathrm{b}}\right), 3.21-3.36\left(\mathrm{~m}, 2 \mathrm{H}, \mathrm{C}_{6} \mathrm{H}_{\mathrm{ab}}\right), 3.54-$ $3.67\left(\mathrm{~m}, 2 \mathrm{H}, \mathrm{C}_{5}{ }^{\prime}\right.$ protons), (3.82-3.87 [m, 1H], 3.99-4.02 [m, 1H], 4.16-4.54 [m, $1 \mathrm{H}]: \mathrm{C}_{2}{ }^{\prime}, \mathrm{C}_{3}{ }^{\prime}$, and $\mathrm{C}_{4}{ }^{\prime}$ protons $), 4.54-4.57(\mathrm{~m}, 1 \mathrm{H}$, $\left.\mathrm{C}_{4} \mathrm{H}\right), 5.74\left(\mathrm{~d}, J=7.9 \mathrm{~Hz}, 1 \mathrm{H}, \mathrm{C}_{1}{ }^{\prime}\right.$ proton).

\section{Synthesis of $\mathrm{N}^{4}$-benzoamido-tetrahydrocytidine (1)}

THU $(0.25 \mathrm{~g})$ was dissolved in $5.2 \mathrm{~mL}$ of $\mathrm{MeOH}$ :water (25:1) and acetic acid was added until an apparent $\mathrm{pH}$ of 3 was attained. Benzohydrazide (1.2 equiv.) was added and the reaction mixture was stirred at $40^{\circ} \mathrm{C}$ for $4 \mathrm{~h}$. Following lyophilization, 1 was purified by preparative TLC (Silica gel, $30 \% \mathrm{MeOH} / \mathrm{DCM}, \mathrm{R}_{\mathrm{f}} 0.3$ ) in $50 \%$ yield. IR (KBr) Vmax cm ${ }^{-1}$ : 3323, 2925, 2501, 1636, 1504, 1073, 1037, 755; ${ }^{1} \mathrm{H}$ NMR $\left(500 \mathrm{MHz}, \mathrm{D}_{2} \mathrm{O}\right) \delta 1.82-1.93$ ( $\mathrm{m}, 2 \mathrm{H}, \mathrm{C}_{5}$ protons), 3.36-3.42 (m, $2 \mathrm{H} \mathrm{C}_{6}$ protons), 3.61-3.72 ( $\mathrm{m}, 2 \mathrm{H}, \mathrm{C}_{5}{ }^{\prime}$ protons), (3.90-3.92 [m, 1H], $4.07[\mathrm{dd}, J=9.5 \mathrm{~Hz}, J=5.5 \mathrm{~Hz}, 1 \mathrm{H}], 4.20-4.25$ $[\mathrm{m}, 1 \mathrm{H}]: \mathrm{C}_{2}{ }^{\prime}, \mathrm{C}_{3}{ }^{\prime}$, and $\mathrm{C}_{4}{ }^{\prime}$ protons $), 4.89-5.07\left(\mathrm{~m}, 1 \mathrm{H}, \mathrm{C}_{4} \mathrm{H}\right), 5.79$

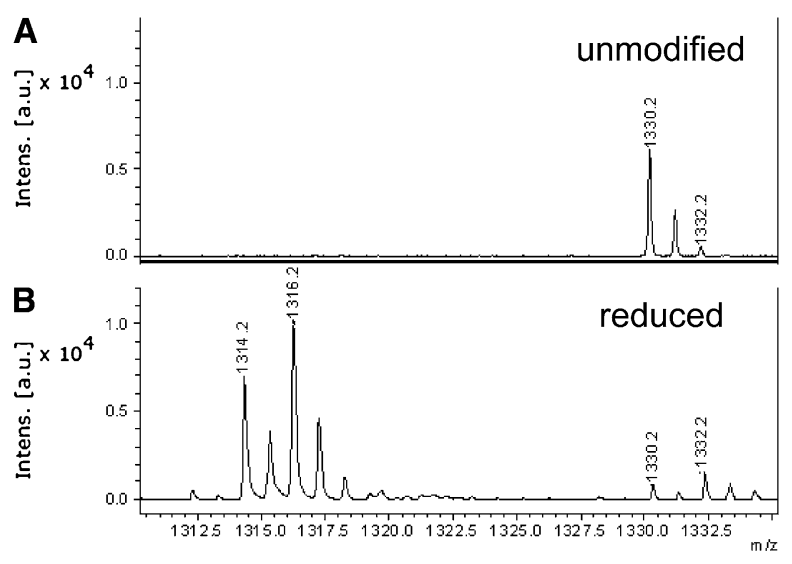

FIGURE 3. MALDI analyses of RNase T1 digests of unmodified tRNA ${ }^{\mathrm{Arg}}$ and $\mathrm{NaBH}_{4}$-reduced tRNA ${ }^{\text {Arg }}$. (A) Unmodified tRNA ${ }^{\mathrm{Arg}}$, showing detail of $1310-1335 \mathrm{~m} / \mathrm{z}$ region and 1330 peak corresponding to unmodified $\mathrm{AD}^{20 \mathrm{a}} \mathrm{AG} 3^{\prime} \mathrm{P}$; $(B)$ same as $A$, but for $\mathrm{NaBH}_{4}{ }^{-}$ reduced tRNA ${ }^{\text {Arg }}$. 

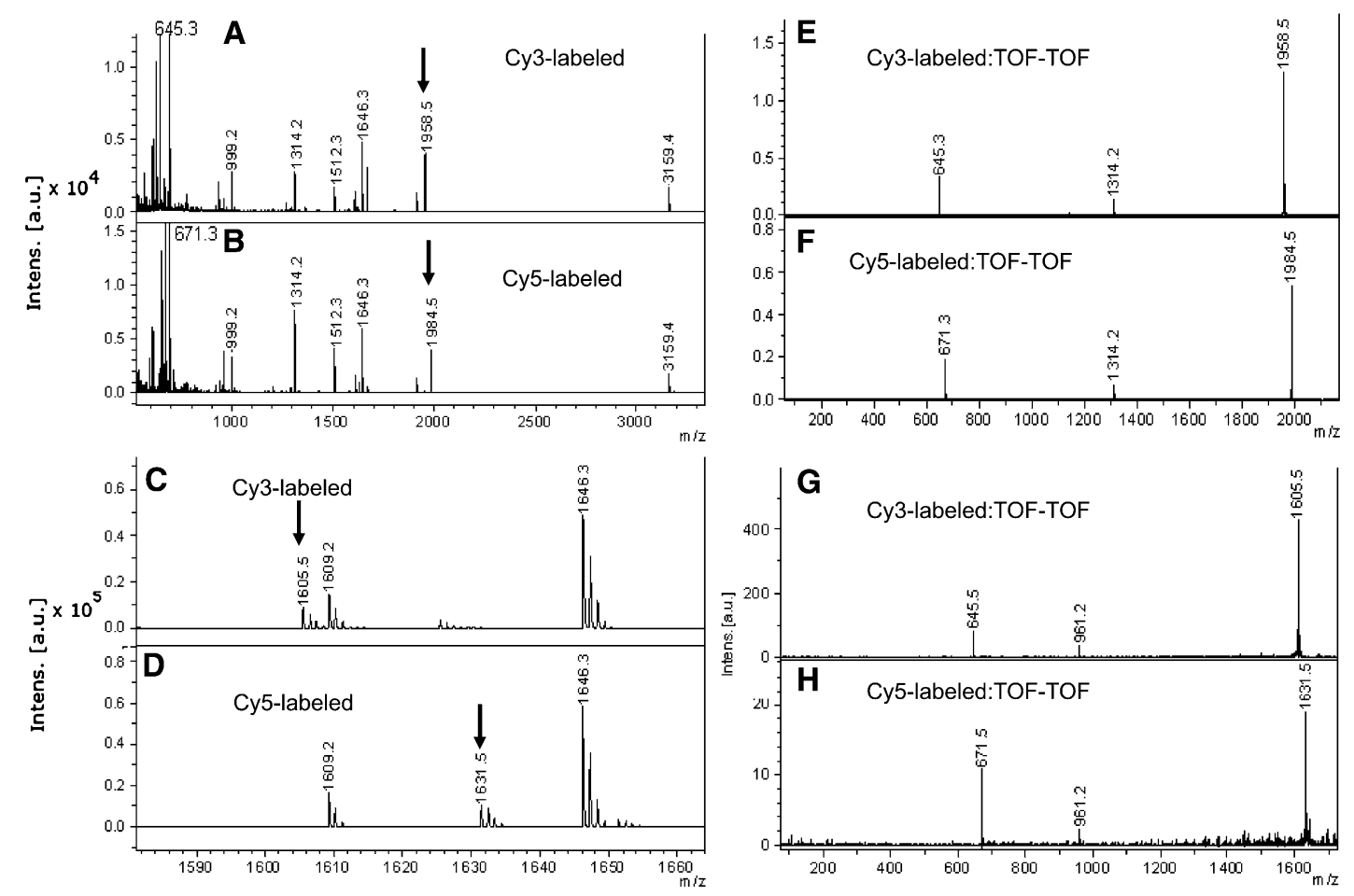

FIGURE 4. MALDI and TOF-TOF analyses of RNase T1 digests of reduced and labeled tRNA ${ }^{\mathrm{Arg}}$. $(A-D)$ : MALDI analyses-arrows indicated new peaks observed on digestion of labeled tRNA ${ }^{\text {Arg }}$. (A) Major peaks, Cy3-labeled tRNA ${ }^{\text {Arg; }}$ (B) major peaks, Cy5-labeled tRNA ${ }^{\text {Arg }}$; $(C)$ detail of $1600-1660 \mathrm{~m} / \mathrm{z}$ region, Cy3-labeled tRNA ${ }^{\mathrm{Arg}}$; $(D)$ detail of $1600-1660 \mathrm{~m} / \mathrm{z}$ region, Cy5-labeled tRNA ${ }^{\mathrm{Arg}}$. $(E-H)$ : TOF-TOF analyses: $(E)$ 1958.5 m/ $z$ peak in $A ;(F) 1984.5 \mathrm{~m} / z$ peak in $B ;(G) 1605.5 \mathrm{~m} / z$ peak in $C ;(H) 1631.5 \mathrm{~m} / z$ peak in $D$.

(d, $J=7.0 \mathrm{~Hz}, 1 \mathrm{H}, \mathrm{C}_{1}{ }^{\prime}$ proton), (7.48-7.49 [m, 2H], 7.51-7.54 [m, $1 \mathrm{H}], 7.76-7.78[\mathrm{~m}, 2 \mathrm{H}]$ : phenyl protons).

\section{Cy3/Cy5 labeling of tRNA}

tRNA $(2.5 \mathrm{mg} / \mathrm{mL})$ was incubated with $\mathrm{NaBH}_{4}(10 \mathrm{mg} / \mathrm{mL}$, added from a $100 \mathrm{mg} / \mathrm{mL}$ stock solution in $10 \mathrm{mM} \mathrm{KOH})$ in $40 \mathrm{mM}$ Tris$\mathrm{HCl}(\mathrm{pH} 7.5)$ at $0^{\circ} \mathrm{C}$ for $60 \mathrm{~min}$, in a total volume of $400 \mu \mathrm{L}$, followed by quenching with $6 \mathrm{~N}$ acetic acid $(80 \mu \mathrm{L})$. Excess reagent was removed by three ethanol precipitations of reduced tRNA, denoted tRNA (red). Dried tRNA (red) $(2 \mathrm{nmol})$ was dissolved in $1.5 \mu \mathrm{L}$ of $0.1 \mathrm{M}$ sodium formate ( $\mathrm{pH} 3.7), 0.2 \mu \mathrm{L}$ of Cy3-hydrazide $(200 \mathrm{mM})$ in DMSO was added, and incubation was carried out for $150 \mathrm{~min}$ at $37^{\circ} \mathrm{C}$. During this period, additional portions $(0.1 \mu \mathrm{L})$ of the Cy3-hydrazide solution were added at 50 and $100 \mathrm{~min}$. Following vacuum drying, the dried sample was dissolved in $400 \mu \mathrm{L}$ of $50 \mathrm{mM}$ sodium acetate at $\mathrm{pH} 6.5$, and unbound dye was removed by three to four cycles of ethanol precipitation.

\section{Proflavin labeling of tRNA}

$\mathrm{NaBH}_{4}$ reduced tRNA $(0.5 \mathrm{mg} / 50 \mu \mathrm{L})$ prepared as described previously was incubated with $1 \mathrm{~mL}$ of $0.1 \mathrm{M} \mathrm{Na}$ formate ( $\mathrm{pH} 3.0$ ) containing $0.52 \mathrm{mg} / \mathrm{mL}$ of proflavin (3,6-diaminoacridine) hemisulfate salt for $45 \mathrm{~min}$ at $37^{\circ} \mathrm{C}$. Following incubation, the reaction mixture was brought to $\mathrm{pH} 7$ with $2 \mathrm{M}$ Tris- $\mathrm{HCl}(\mathrm{pH} 8.5)(\sim 100$ $\mu \mathrm{L}$ ). Unbound proflavin was removed by three to four phenol extractions ( $\mathrm{Na}$ acetate, $\mathrm{pH}$ 6.5), and traces of phenol were removed by one to two chloroform extractions and two cycles of ethanol precipitation.

\section{RNase digestion of tRNAs}

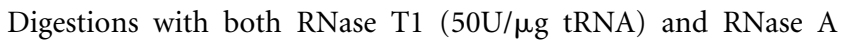
(5U/ $\mu \mathrm{g}$ tRNA) were carried out in ammonium acetate buffer $(220$ $\mathrm{mM}, \mathrm{pH} 6.5,1.5 \mu \mathrm{L}$ ) for $10 \mathrm{~min}$ at $37^{\circ} \mathrm{C}$. Addition of ammonium acetate inhibits formation of alkali salts (Nordhoff et al. 1996), obviating the need for a purification step prior to MS analysis.

\section{Mass spectrometric analysis}

Mass spectrometry experiments were performed on a Bruker Ultraflex MALDI-TOF from Bruker Daltonics having a 3-m effective flight path, a two-stage gridless ion reflector, pulsed ion extraction, and a nitrogen laser $(337 \mathrm{~nm})$. All MALDI spectra were acquired in positive polarity and in reflectron mode. Vendorsupplied Flex control and Flex analysis software were used for data acquisition and processing, respectively. Typically, 200 laser shots were co-added per spectrum. Each spectrum was smoothed using a five-point Savitsky-Golay algorithm and background subtracted. The instrument was calibrated externally with calibrant mixtures provided by Bruker that bracketed the $m / z$ range of interest. LIFT mass spectra were acquired on a Bruker Ultraflex TOF/TOF mass spectrometer operated in the positive ion mode. Metastable fragmentation was induced by a nitrogen laser $(337 \mathrm{~nm})$ without the further use of collision gas. Precursor ions were accelerated to $8 \mathrm{kV}$ 


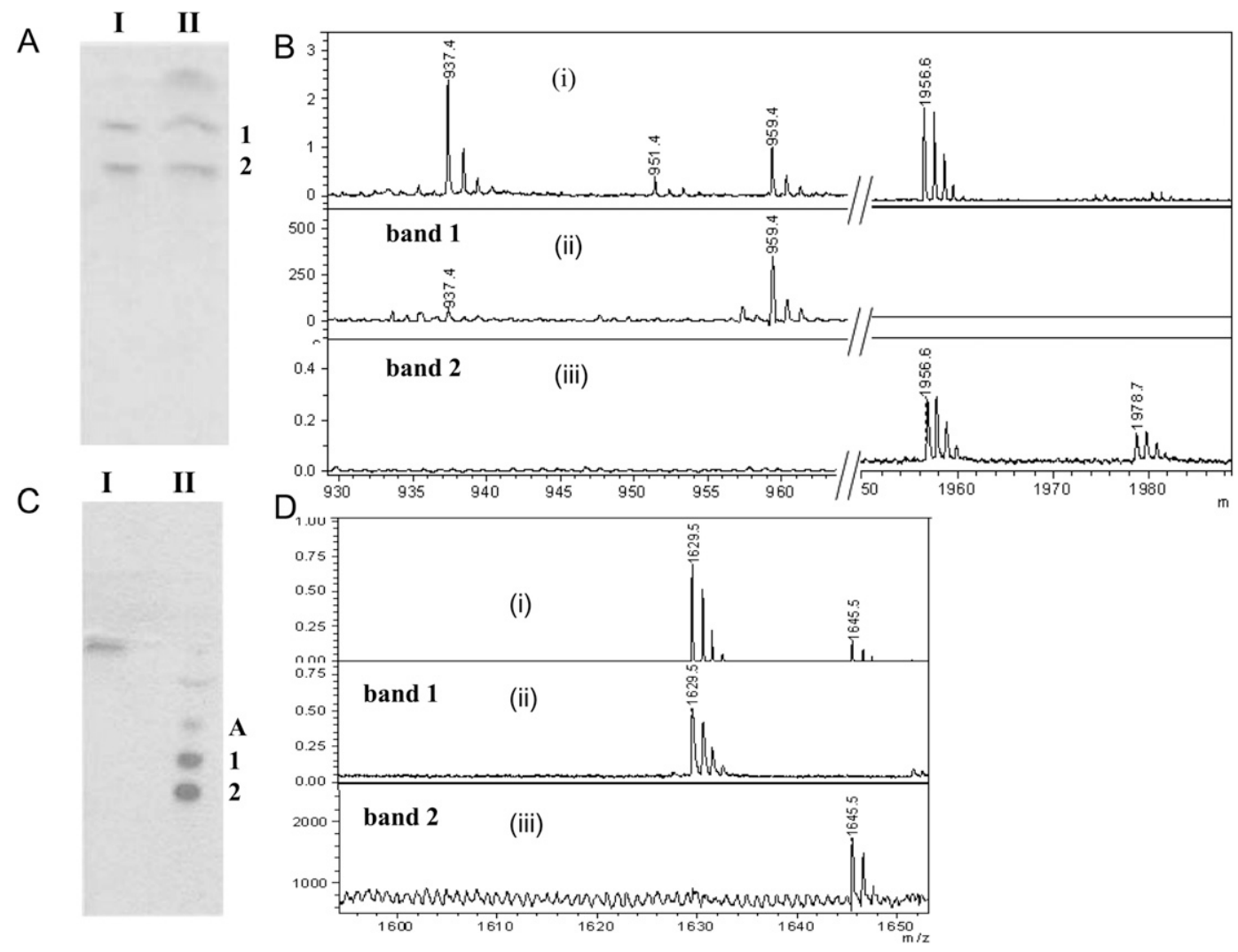

FIGURE 5. Quantification and identification of Cy3-labeled RNase A oligonucleotides. (A) TLC analysis of digest of Cy3-labeled tRNA ${ }^{\text {Arg }}$. Lane $I$, digest; lane II, digest plus added Cy3-hydrazide. (B) MALDI spectra-(i) Cy3-labeled tRNA ${ }^{\text {Arg }}$ digest, showing Cy3-D ${ }^{17}$ peak at $m / z$ 937.4 $(\mathrm{Na}+$ adduct at 959.4) and Cy3-GGAD ${ }^{20 a}$ peak at $\mathrm{m} / \mathrm{z}$ 1956.6, respectively; (ii) and (iii); parallel spectra for bands 1 and $2(A)$, respectively. The peak at $\mathrm{m} / z 1978.7$ corresponds to the Na+ adduct of Cy3-GGAD ${ }^{20 a}$. (C) TLC analysis of digest of Cy3-labeled tRNA ${ }^{\text {Phe }}$. Lane $I$, Cy3-hydrazide; lane $I I$, digest. $(D)$ MALDI spectra-(i): Cy3-labeled tRNA ${ }^{\text {Phe }}$ digest, showing Cy3-AGD ${ }^{16}$ peak at $\mathrm{m} / z 1629.5$ and Cy3-GGD ${ }^{20}$ peak at $m / z 1645.5$, respectively; (ii) and (iii); parallel spectra for bands 1 and 2 (C), respectively.

and selected in a timed ion gate. In the LIFT-cell the fragments were further accelerated to $19 \mathrm{kV}$. The reflector potential was $29 \mathrm{kV}$.

The matrix components were $250 \mathrm{mM}$ THAP in acetonitrile and $300 \mathrm{mM}$ DAHC in water, with each being prepared fresh before use. Equal volumes of THAP and DAHC were combined and then mixed with an equal volume of the sample solution. Approximately $1 \mu \mathrm{L}$ of this sample/matrix solution was spotted on the target MALDI plate. For the MALDI analysis of fragments $<1000$

TABLE 3. Cy3-labeling stoichiometries of tRNAs used for MALDI analysis

\begin{tabular}{ll}
\hline tRNA & Cy3 \\
\hline tRNA $^{\text {Arg }}$ & $1.06^{\mathrm{b}}$ \\
Position 17 & $0.56^{\mathrm{a}}$ \\
Position 20a & $0.50^{\mathrm{a}}$ \\
tRNA & $1.2^{\mathrm{b}}$ \\
Position 16 & $0.49^{\mathrm{a}}$ \\
Position 20 & $0.59^{\mathrm{a}}$ \\
Band A & $0.12^{\mathrm{a}}$ \\
\hline
\end{tabular}

${ }^{a}$ Labeling stoichiometries at individual D positions were determined from eluates of the TLCs shown in Figure 5.

${ }^{\mathrm{b}}$ Overall labeling stoichiometries of the tRNAs analyzed were determined by the ratio of dye absorbance to $A_{260}$. We were unable to characterize band A by MALDI analysis. amu where the background from the matrix is high, such as Cy3-D (molecular weight 937), samples were analyzed using target plates with a hydrophilic anchor (AnchorChip $600 \mu \mathrm{m}$, Bruker) and a 10 -fold reduction in matrix components.

\section{TLC of labeled oligonucleotides}

Labeled fragments were resolved on a silica gel TLC plate (60 F-254) eluted with a freshly prepared solution of water: $\mathrm{NH}_{4} \mathrm{OH}$ : 1-propanol (1:3.5:5.5).

\section{SUPPLEMENTAL MATERIAL}

Supplemental material is available for this article.

\section{ACKNOWLEDGMENTS}

This work is supported by NIH grant nos. GM-071014 and GM080376 and NIST grant no. 70NANB7H7011. We thank Dr. Rakesh Kohli for help in obtaining mass spectra and Professor Yale E. Goldman for valuable discussions. We also thank the developers of the MongoOligo web site.

Received February 11, 2011; accepted April 27, 2011. 


\section{REFERENCES}

Berhane BT, Limbach PA. 2003a. Functional microfabricated sample targets for matrix-assisted laser desorption/ionization mass spectrometry analysis of ribonucleic acids. Anal Chem 75: 1997-2003.

Berhane BT, Limbach PA. 2003b. Stable isotope labeling for matrix-assisted laser desorption/ionization mass spectrometry and post-source decay analysis of ribonucleic acids. J Mass Spectrom 38: 872-878.

Betteridge T, Liu H, Gamper H, Kirillov S, Cooperman BS, Hou YM. 2007. Fluorescent labeling of tRNAs for dynamics experiments. RNA 13: 1594-1601.

Bharill S, Chen C, Stevens B, Kaur J, Smilansky Z, Mandecki W, Gryczynski I, Gryczynski Z, Cooperman BS, Goldman YE. 2011. Enhancement of single-molecule fluorescence signals by colloidal silver nanoparticles in studies of protein translation. ACS Nano 5: 399-407.

Bieling P, Beringer M, Adio S, Rodnina MV. 2006. Peptide bond formation does not involve acid-base catalysis by ribosomal residues. Nat Struct Mol Biol 13: 423-428.

Blanchard SC, Gonzalez RL, Kim HD, Chu S, Puglisi JD. 2004a. tRNA selection and kinetic proofreading in translation. Nat Struct Mol Biol 11: 1008-1014.

Blanchard SC, Kim HD, Gonzalez RL Jr, Puglisi JD, Chu S. 2004b. tRNA dynamics on the ribosome during translation. Proc Natl Acad Sci 101: 12893-12898.

Cerutti P, Miller N. 1967. Selective reduction of yeast transfer ribonucleic acid with sodium borohydride. J Mol Biol 26: 55-66.

Cerutti P, Kondo Y, Landis WR, Witkop B. 1968. Photoreduction of uridine and reduction of dihydrouridine with sodium borohydride. J Am Chem Soc 90: 771-775.

Chen C, Stevens B, Kaur J, Cabral D, Liu H, Wang Y, Zhang H, Rosenblum G, Smilansky Z, Goldman YE, et al. 2011. Singlemolecule fluorescence measurements of ribosomal translocation dynamics. Mol Cell 42: 367-377.

Fei J, Kosuri P, MacDougall DD, Gonzalez RL Jr. 2008. Coupling of ribosomal L1 stalk and tRNA dynamics during translation elongation. Mol Cell 30: 348-359.

Grigoriadou C, Marzi S, Kirillov S, Gualerzi CO, Cooperman BS, 2007a. A quantitative kinetic scheme for $70 \mathrm{~S}$ translation initiation complex formation. J Mol Biol 373: 562-572.

Grigoriadou C, Marzi S, Pan D, Gualerzi CO, Cooperman BS. 2007b. The translational fidelity function of IF3 during transition from the $30 \mathrm{~S}$ initiation complex to the $70 \mathrm{~S}$ initiation complex. $J \mathrm{Mol}$ Biol 373: 551-561.

Hanze AR. 1967. Nucleic acids. IV. The catalytic reduction of pyrimidine nucleosides (human liver deaminase inhibitors). I Am Chem Soc 89: 6720-6725.

Hartmer R, Strom N, Boecker S, Rodi CP, Hillenkamp F, Jurinke C, Boom DV. 2003. RNase T1 mediated base-specific cleavage and MALDI-TOF MS for high-throughput comparative sequence analysis. Nucleic Acids Res 31: e47. doi: 10.1093/nar/gng047.

Hengesbach M, Meusburger M, Lyko F, Helm M. 2008. Use of DNAzymes for site-specific analysis of ribonucleotide modifications. RNA 14: 180-187.

Hossain M, Limbach PA. 2007. Mass spectrometry-based detection of transfer RNAs by their signature endonuclease digestion products. RNA 13: 295-303.

Hossain M, Limbach PA. 2009. Multiple endonucleases improve MALDI-MS signature digestion product detection of bacterial transfer RNAs. Anal Bioanal Chem 394: 1125-1135.
Kirpekar F, Douthwaite S, Rosepstorff P. 2000. Mapping posttranscriptional modifications in $5 \mathrm{~S}$ ribosomal RNA by MALDI mass spectrometry. RNA 6: 296-306.

Li LS, Morales JC, Veigl M, Sedwick D, Greer S, Meyers M, Wagner M, Fishel R, Boothman DA. 2009. DNA mismatch repair (MMR)dependent 5-fluorouracil cytotoxicity and the potential for new therapeutic targets. Br J Pharmacol 158: 679-692.

McIntosh B, Ramachandiran V, Kramer G, Hardesty B. 2000. Initiation of protein synthesis with fluorophore-Met-tRNA(f) and the involvement of IF-2. Biochimie 82: 167-174.

Meng Z, Limbach PA. 2004. RNase mapping of intact nucleic acids by electrospray ionization fourier transform ion cyclotron resonance mass spectrometry (ESI-FTICRMS) and ${ }^{18} \mathrm{O}$ labeling. Int J Mass Spectrom 234: $37-44$.

Munro JB, Altman RB, O'Connor N, Blanchard SC. 2007. Identification of two distinct hybrid state intermediates on the ribosome. Mol Cell 25: 505-517.

Nordhoff E, Kirpekar F, Roepstorff P. 1996. Mass spectrometry of nucleic acids. Mass Spectrom Rev 15: 67-138.

Pan D, Kirillov SV, Cooperman BS. 2007. Kinetically competent intermediates in the translocation step of protein synthesis. Mol Cell 25: 519-529.

Pan D, Qin H, Cooperman BS. 2009. Synthesis and functional activity of tRNAs labeled with fluorescent hydrazides in the D-loop. RNA 2: $346-354$.

Pape T, Wintermeyer W, Rodnina MV. 1998. Complete kinetic mechanism of elongation factor Tu-dependent binding of aminoacyl-tRNA to the A site of the E. coli ribosome. EMBO J 17: 74907497.

Paryzek Z, Tabaczka B. 2001. The Preparation of 1-Allyluracil. N(1)Alkylation of N(3)-Protected Uracil Derivatives. Org Prep Proced Int 33: 400-404.

Polo LM, Limbach PA. 1998. Matrix-assisted laser desorption/ionization time-of-flight mass spectrometry for the analysis of RNase H cleavage products. J Mass Spectrom 33: 1226-1231.

Savelsbergh A, Katunin VI, Mohr D, Peske F, Rodnina MV, Wintermeyer W. 2003. An elongation factor G-induced ribosome rearrangement precedes tRNA-mRNA translocation. Mol Cell 11: 15171523.

Schleich HG, Wintermeyer W, Zachau HG. 1978. Replacement of wybutine by hydrazines and its effect on the active conformation of yeast tRNA ${ }^{\text {Phe }}$. Nucleic Acids Res 5: 1701-1713.

Wentworth DF, Wolfenden R. 1975. On the interaction of 3,4,5,6tetrahydrouridine with human liver cytidine deaminase. Biochemistry 23: 5099-5105.

Wintermeyer W, Zachau HG. 1971. Replacement of Y base, dihydrouracil, and 7-methylguanine in tRNA by artificial odd bases. FEBS Lett 18: 214-218.

Wintermeyer W, Zachau HG. 1974. Replacement of odd bases in tRNA by fluorescent dyes. Methods Enzymol 29: 667673.

Wintermeyer W, Zachau HG. 1979. Fluorescent derivatives of yeast tRNA. Eur J Biochem 98: 465-475.

Woolhead CA, McCormick PJ, Johnson AE. 2004. Nascent membrane and secretory proteins differ in FRET-detected folding far inside the ribosome and in their exposure to ribosomal proteins. Cell 116: $725-736$.

Zhao X, Yu YT. 2004. Detection and quantitation of RNA base modifications. RNA 10: 996-1002. 

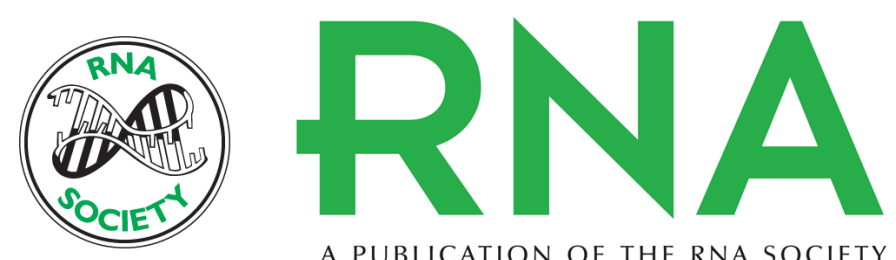

A PUBLICATION OF THE RNA SOCIETY

\section{Fluorescent labeling of tRNA dihydrouridine residues: Mechanism and distribution}

Jaskiran Kaur, Monika Raj and Barry S. Cooperman

RNA 2011 17: 1393-1400 originally published online May 31, 2011

Access the most recent version at doi:10.1261/rna.2670811

\section{Supplemental http://rnajournal.cshlp.org/content/suppl/2011/05/13/rna.2670811.DC1 \\ Material}

References This article cites 37 articles, 7 of which can be accessed free at:

http://rnajournal.cshlp.org/content/17/7/1393.full.html\#ref-list-1

\section{License}

Email Alerting Receive free email alerts when new articles cite this article - sign up in the box at the Service top right corner of the article or click here.

To subscribe to RNA go to:

http://rnajournal.cshlp.org/subscriptions 